\title{
SISTEM INFORMASI PENGELOLAAN DATA PASIEN RAWAT JALAN KLINIK PRATAMA ANUGRAH DEMAK BERBASIS WEB DENGAN NOTIFIKASI TELEGRAM
}

\author{
Diana Laily Fithri ${ }^{1}$, Noor Latifah ${ }^{2}$, Lina Anjelina ${ }^{3}$ \\ ${ }^{1,2,3}$ Fakultas Teknik, Program Studi Sistem Informasi, Universitas Muria Kudus
}

\section{Article Info:}

Dikirim: 06 Mei 2020

Direvisi: 30 Juni 2020

Diterima: 30 Juni 2020

Tersedia Online: 30 Juni 2020

Penulis Korespondensi:

Diana Laily Fithri

Universitas Muria Kudus, Kudus,

Indonesia

Email: diana.laily@umk.ac.id

\begin{abstract}
Abstrak: Klinik merupakan tempat atau sarana yang berguna untuk membantu menyembuhkan penyakit masyarakat yang mengalami gangguan kesehatan tanpa harus datang ke rumah sakit. Sistem pelayanan yang masih menggunakan sistem lama atau manual, tentu dapat menghambat proses penanganan penyembuhan penyakit yang diderita pasien. Sistem ini digunakan untuk mempercepat proses kinerja pada klinik seperti pengecekan data pasien ataupun rekam medis pasien, pengelolaan obat dan meringankan beban kerja dari pegawai klinik dan dokter sehingga proses kerja menjadi lebih cepat. Sistem ini dapat memberikan notifikasi nomer antrian melalui Telegram dan memudahkan pasien dalam melakukan pendaftaran pemeriksaan secara online sehingga pasien tidak perlu lagi menunggu lama. Dalam pembangunan aplikasi ini menggunakan bahasa pemrograman PHP dan databasenya menggunakan $M y S Q L$.
\end{abstract}

Kata kunci: pasien; rawat jalan; klinik, telegram.

\begin{abstract}
The clinic is a place or facility that is useful to help cure the illnesses of people who experience health problems without having to come to the hospital. Service systems that are still using the old system or manual, of course can hamper the process of handling the healing of illnesses suffered by patients. This system is used to speed up the performance process at the clinic such as checking patient data or patient medical records, managing drugs and alleviating the workload of clinic staff and doctors so that the work process becomes faster. This system can provide notification of the queue number via Telegram and make it easier for patients to register for an online examination so that patients no longer have to wait long. In the development of this application using the PHP programming language and its database using MYSQL.
\end{abstract}

Keywords: patient; outpatient; clinic; telegram. 


\section{PENDAHULUAN}

Kemajuan teknologi informasi saat ini sangatlah pesat. Hampir semua bidang pemerintahan maupun swasta menggunakan teknologi informasi untuk membantu dan mempermudah pekerjaan manusia dalam pelayanan di bidang pendidikan, kesehatan, bisnis, perbankan dan lain sebagainya. Salah satunya kemajuan teknologi informasi dapat diimplementasikan ke bidang kesehatan sekelas klinik. Karena dalam pelayanan kesehatan seperti klinik membutuhkan data yang cepat untuk meningkatkan pelayanan pada klinik.

Klinik Pratama Anugrah merupakan salah satu badan usaha jasa di bidang pelayanan kesehatan untuk masyarakat yang bertempat tinggal di Ds Mranak Kec Wonosalam Kab Demak. Klinik Pratama Anugrah buka setiap hari, kurang lebih ada 30-40 pasien datang berobat setiap harinya. Klinik Pratama Anugrah memiliki 5 dokter tetap dan 4 pegawai. Semakin berkembangnya layanan pada klinik, semakin meningkat pula jumlah pasien yang berobat pada Klinik Pratama Anugrah. Dengan hal tersebut, maka perlu adanya peningkatan pelayanan yang diberikan kepada pasien.

Proses berobat pada Klinik Pratama Anugrah yaitu semua pasien harus melalui bagian pendaftaran untuk melakukan pendaftaran pasien. Pasien yang baru pertama kali berobat akan diminta mengisi data pasien terlebih dahulu untuk mendapatkan kartu pasien yang akan digunakan selama menjadi pasien di Klinik Pratama Anugrah. Jika pasien yang lama menunjukkan kartu pasien yang berisi nomor rekam medis pasien untuk selanjutnya disiapkan kartu yang berisi rekam medis, untuk dapat melakukan pemeriksaan selanjutnya. Setelah mendapatkan pemeriksaan, pasien menerima resep obat dan selanjutnya diserahkan pada bagian apotek untuk disiapkan obat. Setelah bagian apotek menyiapkan obat pasien, bagian apotek menyerahkan obat dan nota ke bagian pembayaran. Selanjutnya bagian pembayaran memberikan tagihan pemeriksaan dan nota pembelian obat kepada pasien, kemudian pasien membayar tagihan dan menerima obat.

Sistem pengelolaan data yang sudah ada masih dilakukan dengan manual, yaitu sistem catat dan hitung ke dalam buku besar yang menyebabkan terjadi beberapa kendala yang terkadang dapat menghambat kinerja administrasi klinik. Seperti halnya pada antrian pasien, pasien harus menunggu lama untuk di panggil nomor antriannya, lamanya pelayanan dalam mencari data pasien untuk memastikan apakah pasien tersebut telah terdaftar atau belum, pendataan rekam medis juga mengalami banyak kesulitan karena petugas hanya mengelompokkan kartu hasil pemeriksaan medis menjadi rekam medis, petugas klinik kesulitan untuk mengetahui data rekapitulasi obat karena tidak ada laporan rekapitulasi obat seperti stok obat dan tanggal kadaluwarsa obat, proses pembayaran sering terjadi kesalahan perhitungan karena petugas harus menghitung secara manual dengan kalkulator ataupun handphone dan ketika menangani registrasi pasien BPJS membutuhkan waktu yang lama karena harus mencocokkan data pasien dengan mencari data yang telah tercatat pada buku besar secara manual.

Haryanto dalam penelitiannya pada Klinik Yadika Tangerang menjelaskan bahwa sistem informasi yang ada belum memanfaatkan teknologi dan menggunakan cara manual atau belum terkomputerisasi. Sistem informasi pengolahan data pasien merupakan suatu sistem yang mengatur dan mengelola data pasien, membantu memberikan serta menyajikan informasi mengenai data rekam medis. Sistem ini juga membantu petugas pada instansi kesehatan untuk mengelola informasi rekam medis pasien. [1]

Astuti dalam penelitiannya di Klinik ST Di Bandung menjelaskan bahwa Klinik ST belum memiliki suatu perangkat pengelolaan data, terutama dalam hal pencatatan rekam medis pasien, pengadaan barang, serta pembuatan laporan sehingga dibutuhkan sistem informasi rawat jalan untuk menunjang kegiatan operasional klinik yang mencakup layanan rawat jalan serta pengelolaan persediaan barang agar lebih cepat dan efisien dan meningkatkan kualitas pelayanan. [2]

Indarti dalam penelitiannya pada Klinik Umum Galur Medika Jakarta Pusat menjelaskan bahwa dalam hal pengolahan data pendaftaran pasien, sampai pembuatan laporan yang di cetak secara manual, sehingga dalam proses pendaftaran pasien sampai pembuatan laporan seperti, laporan data pasien, laporan registrasi kunjungan pasien, banyak terjadi kesalahan dan membutuhkan proses yang cukup lama. Maka dari itu perlu adanya penerapan sistem aplikasi sehingga dalam menangani masalah pendaftaran pasien serta pembuatan laporan dengan menggunakan komputer melalui program berbasis website menjadi lebih mudah, cepat dan akurat. [3]

Rizky dalam penelitiannya menjelaskan tentang sistem pengelolaan data yang sudah ada di Klinik Andalan masih dilakukan dengan manual. Oleh karena itu, terkadang masih terjadi kesalahan dalam pencarian data pasien, serta proses pengolahan data yang cukup lama sehingga data yang di hasilkan masih kurang akurat dan kurang efisien dalam pembuatan laporan karena membutuhkan waktu yang cukup lama. Dengan adanya aplikasi tersebut diharapkan memperbaiki sistem yang telah ada sebelumya dan dapat meningkatkan kualitas pelayanan serta informasi yang dibutuhkan pasien agar dapat diterima secara cepat dan tepat. [4]

Silalahi dalam penelitiannya menjelaskan tentang solusi terhadap setiap permasalahan yang ada di Klinik Siliwangi seperti halnya pencatatan data pasien, pencatatan rekam medis, kelola ruang rawat jalan, kelola obat dan perhitungan biaya selama pasien dirawat dan juga susahnya melihat jumlah pasien rawat jalan dalam hari, bulan, dan tahun, dimana proses tersebut masih dilakukan secara manual yang memungkinkan terjadinya kesalahan dalam setiap proses yang ada. Dari permasalahan tersebut peneliti membuat aplikasi rawat jalan yang mampu mengelola data dan juga memberikan reminder kepada pasien melalui sms gateway.[5] 
Berdasarkan perbandingan beberapa penelitian dan permasalahan rawat jalan pada Klinik Pratama Anugrah masih belum melakukan pelaporan bulanan terkait rawat jalan secara rinci seperti pelaporan data pasien rawat jalan, pelaporan rekam medis pasien dan laporan keuangan. Pemilik klinik hanya mengandalkan pada catatan tertulis pada buku mengenai jumlah pasien rawat jalan, perhitungan biaya pemeriksaan dan pendataan stok obat.

Dari permasalahan yang sudah di uraikan, maka dibutuhkan suatu sistem infomasi yang dapat membantu menyelesaikan masalah di Klinik Pratama Anugrah. Maka perlu dibuat suatu Aplikasi Pengelolaan Data Pasien Rawat Jalan untuk meningkatkan proses kinerja Klinik Pratama Anugrah seperti yang semula pasien harus menunggu lama untuk antri nantinya akan dapat notifikasi antrian dengan Telegram sehingga pasien tidak menunggu terlalu lama, pendataan pasien, pendataan rekam medis pasien dan pendataan administrasi klinik yang semula manual menggunakan catatan pada buku akan menjadi terkomputerisasi yang akan menghasilkan laporan yang lebih terinci.

\section{METODOLOGI PENELITIAN}

Proses pengembangan sistem merupakan salah satu proses terpenting dalam analisa sistem. Metode pengembangan sistem yang digunakan dalam perancangan sistem informasi pengelolaan data pasien rawat jalan adalah dengan menggunakan metode Waterfall. Menurut Sukamto dan Shalahuddin, model air terjun menyediakan pendekatan alur hidup perangkat lunak secara sekuensial atau terurut dimulai dari analisis, desain, pengkodean, pengujian, dan tahap pendukung (support). [6]

Dalam pengembangan metode Waterfall terdapat beberapa tahapan dari pengembangan sistem, yaitu: analisis kebutuhan perangkat lunak spesifikasi kebutuhan perangkat lunak dalam penelitian ini adalah sebagai berikut:
a. Metode RPL
: Waterfall
b. Perancangan : UML (Unified Modelling Language)
c. Software
: Sublime Text 3, Xampp, Chrome
d. Coding
e. Database
f. Testing
: PHP, Javascript
: Black Box

\subsection{Desain}

Desain perangkat lunak adalah proses multi langkah yang fokus pada desain pembuatan program perangkat lunak termasuk struktur data, arsitektur perangkat lunak, representasi antarmuka seperti sistem dan user/pengguna, dan prosedur pengodean. Tahap ini mentranslasi kebutuhan perangkat lunak dari tahap analisis kebutuhan ke representasi desain agar dapat diimplementasikan menjadi program pada tahap selanjutnya.

\subsection{Pembuatan Kode Program}

Desain harus ditranslasikan ke dalam program perangkat lunak. Hasil dari tahap ini adalah program komputer sesuai dengan desain yang telah dibuat pada tahap desain. Aplikasi yang digunakan untuk coding adalah PHP, Javascript yang disesuai dengan desain yang telah dibuat pada tahap desain.

\subsection{Pengujian}

Pengujian pada sistem ini menggunakan pengujian Black Box. Hal ini dilakukan untuk meminimalisir kesalahan (error) dan memastikan keluaran yang dihasilkan sesuai dengan yang diinginkan.

\subsection{Pendukung (support) atau pemeliharaan (maintenance)}

Tidak menutup kemungkinan sebuah perangkat lunak mengalami perubahan ketika sudah dikirimkan ke user. Perubahan bisa terjadi karena adanya kesalahan yang muncul dan tidak terdeteksi saat pengujian atau perangkat lunak harus beradaptasi dengan lingkungan baru. Tahap pendukung atau pemeliharaan dapat mengulangi proses pengembangan mulai dari analisis spesifikasi untuk perubahan perangkat lunak yang sudah ada, tapi tidak untuk membuat perangkat lunak baru. Namun tahap ini tidak dilaksanakan. 


\section{HASIL DAN PEMBAHASAN}

\subsection{Analisa Sistem Lama}

\subsubsection{FOD (Flow of Document) Dari Alur Pendaftaran Pasien}

FOD pendaftaran pasien menggambarkan tentang alur pendaftaran pasien yang dimulai dengan pasien mendaftar kemudian dilakukan pengecekan oleh admin klinik. Gambar 1 menjelaskan gambar tentang alur pendaftaran pasien.

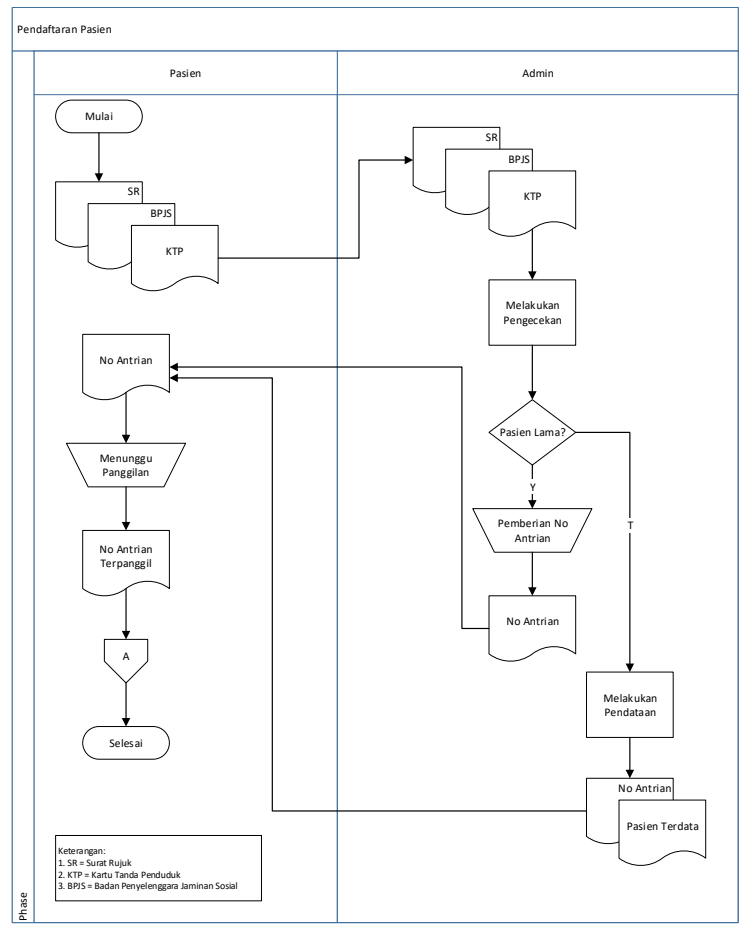

Gambar 1. FOD Pendaftaran Pasien

\subsubsection{FOD (Flow of Document) Dari Alur Pemeriksaan Pasien}

FOD alur pemeriksaan pasien menggambarkan tentang pemeriksaan antara pasien dengan dokter, yang dimulai dengan mendapatkan no antrian yang didapatkan oleh pasien kemudian dilakukan pemeriksaan oleh Dokter sampai dengan pasien mendapat resep obat yang diberikan kepada pasien. Gambar 2 menjelaskan tentang alur pemeriksaan pasien.

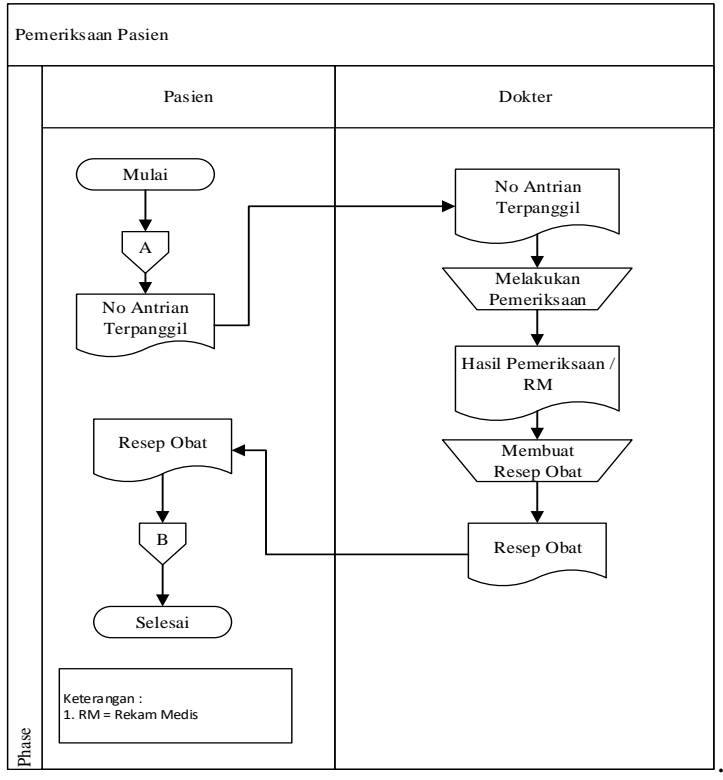

Gambar 2. FOD Pemeriksaan Pasien 


\subsubsection{FOD (Flow of Document) Dari Alur Penebusan Resep}

FOD penebusan resep menggambarkan tentang alur antara pasien, apoteker dan admin dalam pemberian resep kepada pasien. Gambar 3 menjelaskan tentang penebusan resep sampai dengan pemberian resep yang diberikan kepada pasien.

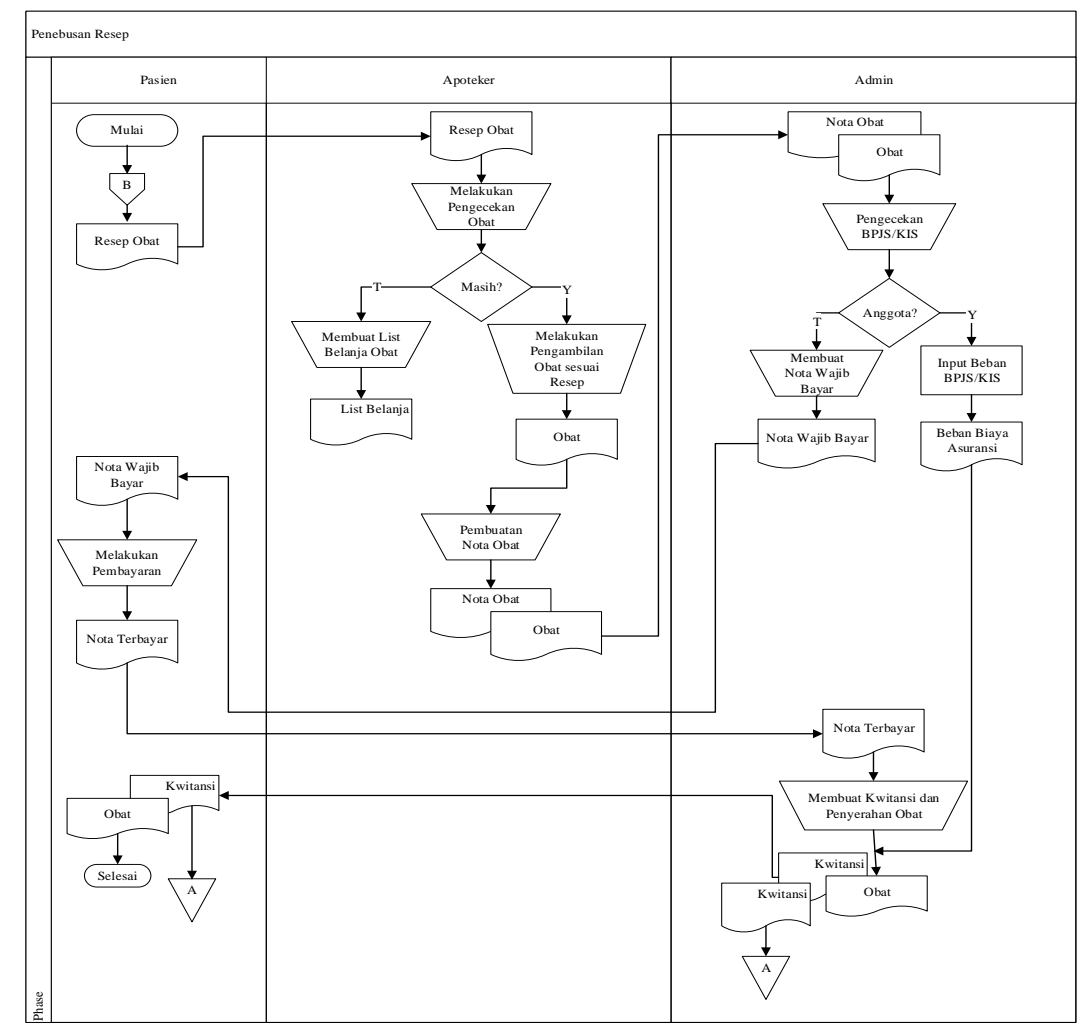

Gambar 3. FOD Penebusan Resep

\subsection{Analisa dan Rancangan Sistem Baru}

Klinik Pratama Anugrah merupakan salah satu badan usaha jasa di bidang pelayanan kesehatan untuk masyarakat yang bertempat tinggal di Ds Mranak Kec Wonosalam Kab Demak. Klinik Pratama Anugrah buka setiap hari, kurang lebih ada 30-40 pasien datang berobat setiap harinya. Klinik Pratama Anugrah memiliki 5 dokter tetap dan 4 pegawai. Semakin berkembangnya layanan pada klinik, semakin meningkat pula jumlah pasien yang berobat pada Klinik Pratama Anugrah. Dengan hal tersebut, maka perlu adanya peningkatan pelayanan yang diberikan kepada pasien.

Sistem pengelolaan data yang sudah ada masih dilakukan dengan manual, yaitu sistem catat dan hitung ke dalam buku besar yang menyebabkan terjadi beberapa kendala yang terkadang dapat menghambat kinerja administrasi klinik. Selain itu pada Klinik Pratama Anugrah masih belum melakukan pelaporan bulanan terkait rawat jalan secara rinci seperti pelaporan data pasien rawat jalan, pelaporan rekapitulasi obat per bulan dan keuangan setiap bulannya. Pemilik klinik hanya mengandalkan pada catatan tertulis pada buku mengenai jumlah pasien rawat jalan, perhitungan biaya pemeriksaan dan pendataan stok obat.

\subsubsection{Bussiness Use Case}

Business Use Case dari proses bisnis yang berjalan pada klinik pratama anugrah demak dapat dilihat pada gambar dibawah ini. Dalam business use case memiliki 4 aktor, yaitu pasien, dokter, admin dan apoteker. Dalam bisnis use case menunjukkan gambaran hubungan antara proses yang satu dengan proses yang lainnya. Gambar 4 menggambarkan tentang bisnis use case diagram pengelolaan pasien rawat jalan. 


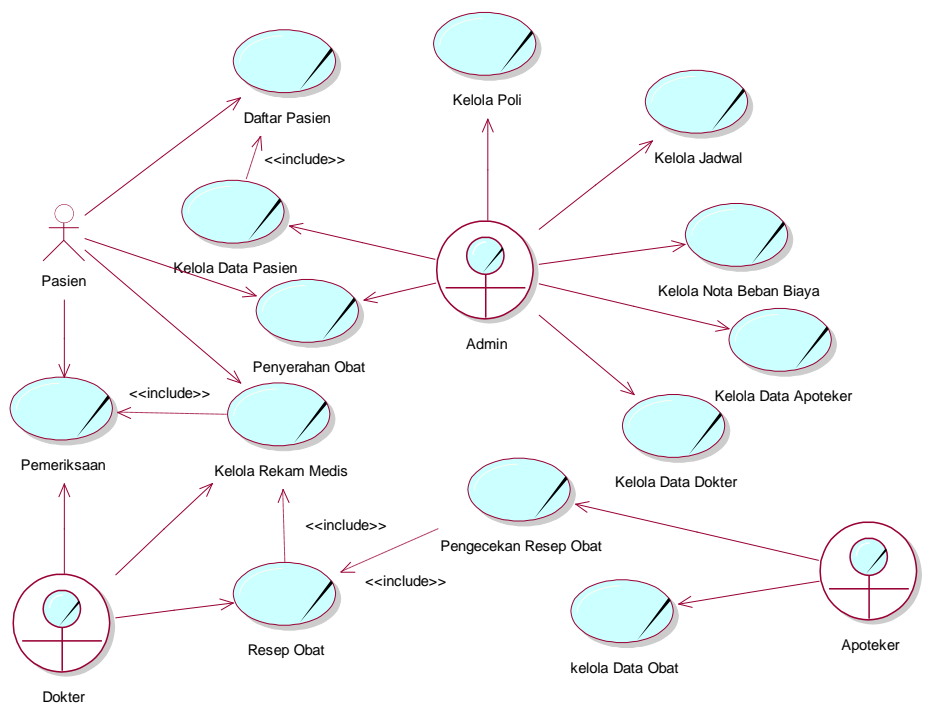

Gambar 4. Bisnis Use Case Pengelolaan Pasien Rawat Jalan

\subsubsection{System Use Case}

Sistem Use Case dari sistem informasi pengelolaan data pasien rawat jalan klinik pratama anugrah demak berbasis web dengan notifikasi telegram dapat dilihat pada gambar dibawah ini. Dalam use case diagram memiliki 4 aktor yaitu admin, pasien, apoteker dan dokter. Gambar 5 menggambarkan tentang use case diagram pengelolaan rawat jalan.

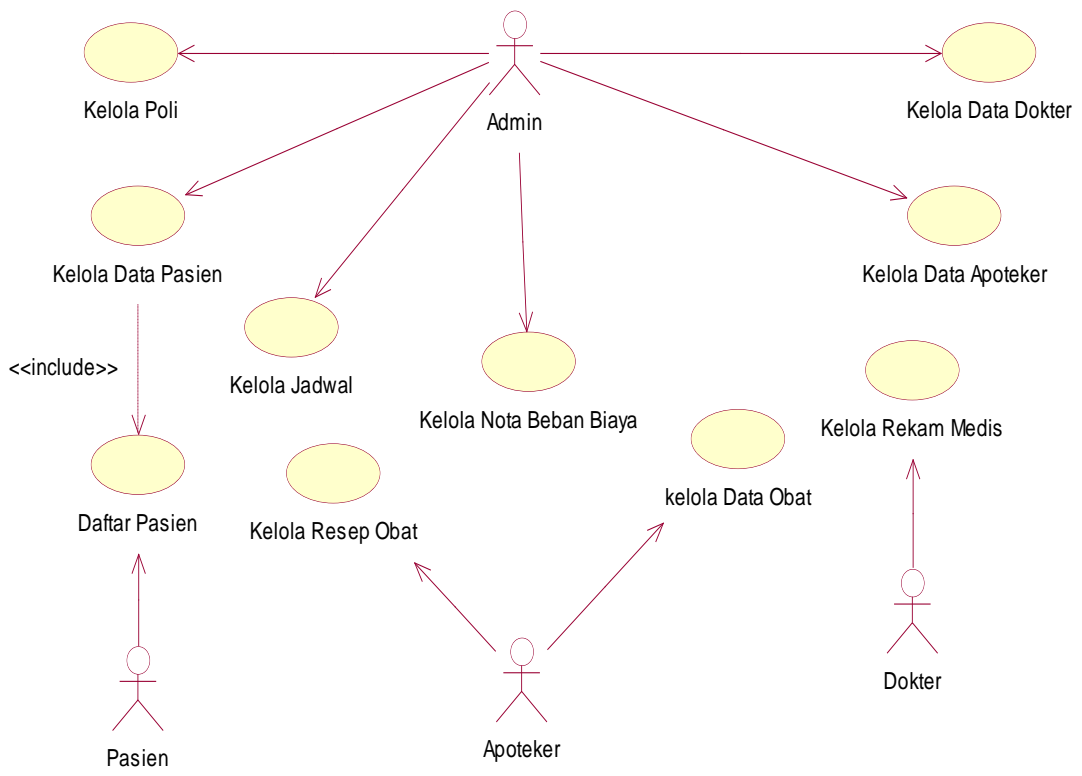

Gambar 5. Use Case Diagram Pengelolaan Rawat Jalan

\subsubsection{Class Diagram}

Class Diagram dari sistem informasi pengelolaan data pasien rawat jalan klinik pratama anugrah demak berbasis web dengan notifikasi telegram. Gambar 6 menggambarkan tentang class diagram dalam pengelolaan rawat jalan. 


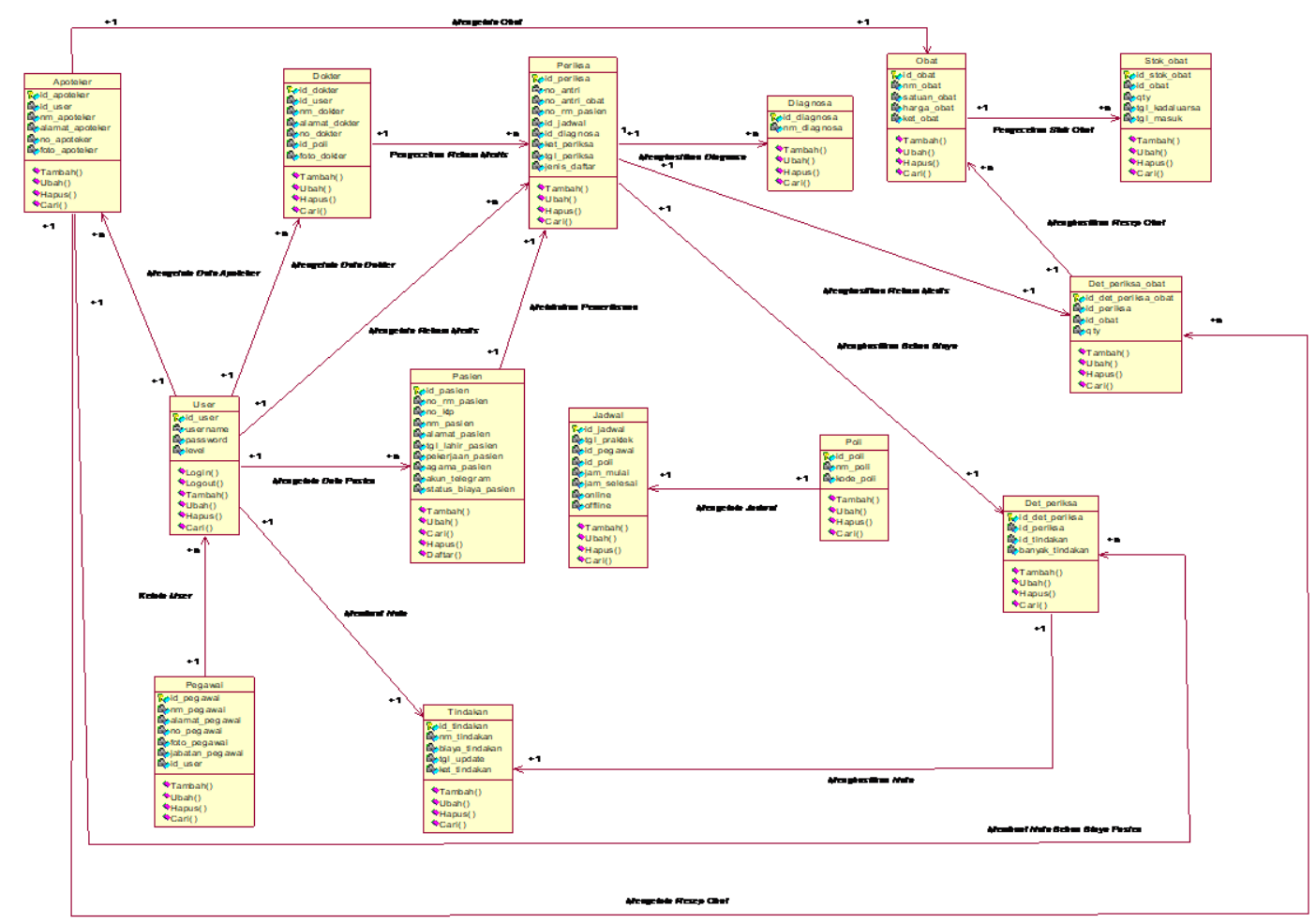

Gambar 6. Class Diagram Pengelolaan Rawat Jalan

\subsubsection{Entity Relattionship Diagram}

ERD dari sistem informasi pengelolaan data pasien rawat jalan klinik pratama anugrah demak berbasis web dengan notifikasi telegram dapat dilihat pada gambar dibawah ini. Gambar 7 menjelaskan tentang ERD (Entity Relationship Diagram).

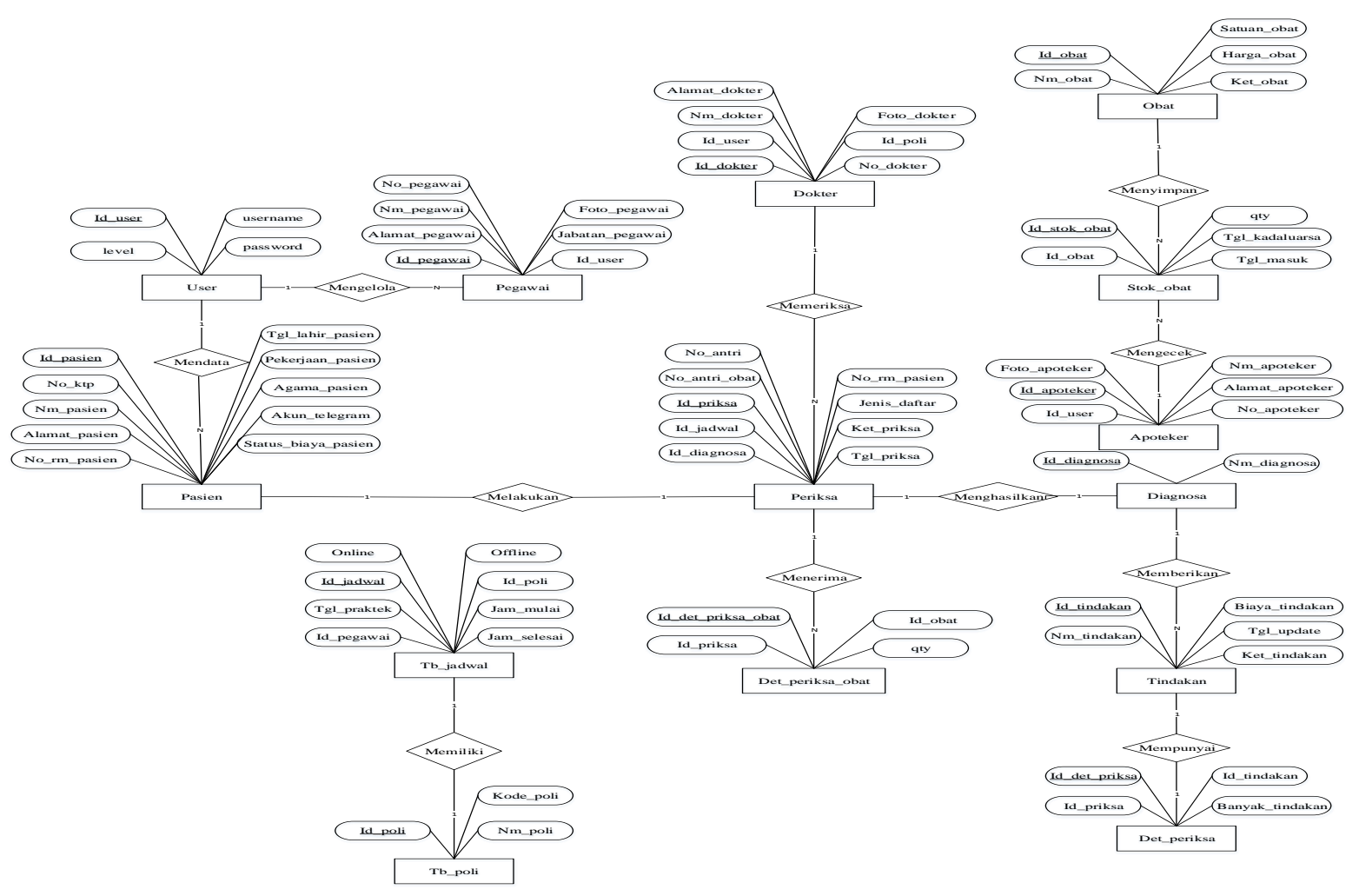

Gambar 7. ERD (Entity Relationship Diagram) 


\subsubsection{Relasi Tabel}

Relasi Tabel dari sistem informasi pengelolaan data pasien rawat jalan klinik pratama anugrah demak berbasis web dengan notifikasi telegram menggambarkan tentang hubungan antara beberapa table yang saling berelasi satu dengan yang lainnya. Gambar 8 menunjukkan relasi table antara beberapa tabel.

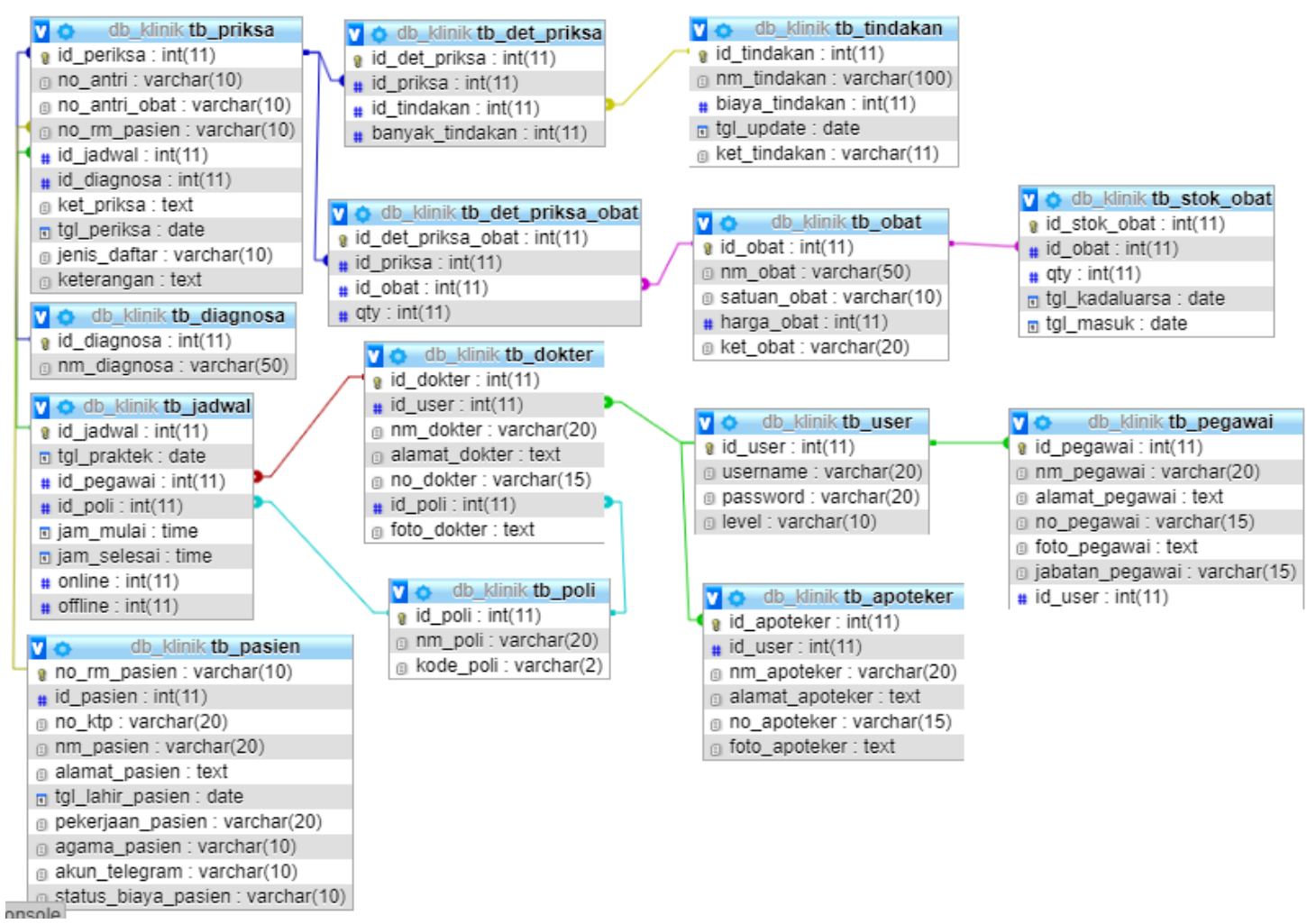

Gambar 8. Relasi Tabel Pengelolaan Rawat Jalan

\subsubsection{Implementasi}

1. Halaman Utama Admin

Halaman ini merupakan tampilan halaman utama pasien, terdiri dari dashboard yang menampilkan daftar periksa, rekam medis, lihat poli dan lihat jadwal. Ada sub menu akun yang terdapat profil dan logout. Gambar 10 menunjukkan halaman utama admin dalam aplikasi sistem pengelolaan pasien rawat jalan.

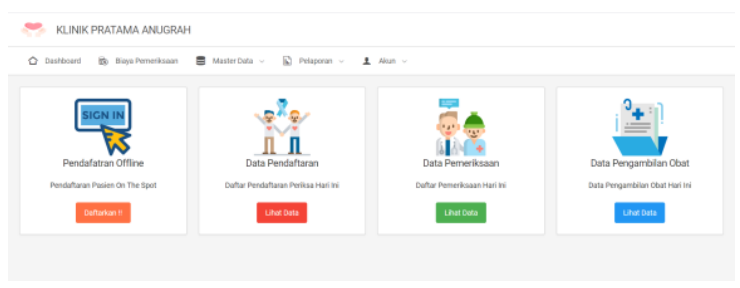

Gambar 9. Halaman Utama Admin

2. Halaman Utama Apoteker

Halaman ini merupakan halaman utama apoteker. Dashboard halaman apoteker meliputi data antrian obat dan data antrian terselesaikan. Kemudian terdapat sub menu yang meliputi data transaksi obat, master kelola obat dan akun. Terdapat notif untuk kadaluarsa obat. Gambar 11 menggambarkan tentang halaman utama apoteker. 


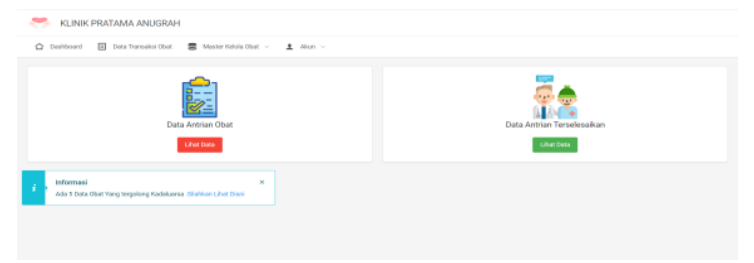

Gambar 10. Halaman Utama Apoteker

\section{Halaman Telegram}

Halaman ini berfungsi untuk memberikan informasi tentang nomor antrian jika pasien sudah mendaftar dan informasi nomer rekam medis apabila pasien lupa dengan nomer rekam medisnya. Gambar 12 menunjukkan tentang halaman notifikasi telegram dalam sistem pengelolaan pasien rawat jalan

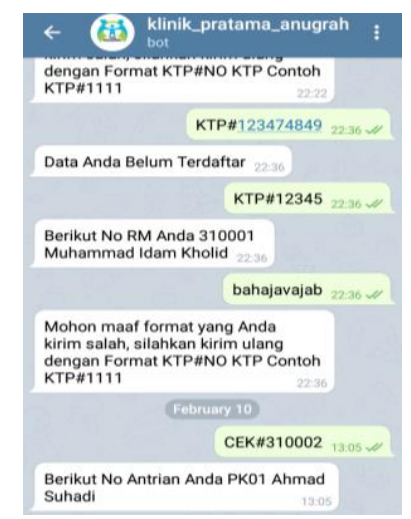

\section{Gambar 11. Halaman Notifikasi Telegram}

\subsubsection{Test Case Data Rekam Medis}

Pengujian pada bagaian ini untuk melakukan beberapa tes dari proses atau kekurangan pada bagian yang berkaitan dengan kelola data rekam medis. Berikut adalah tabel 4.3 untuk pengujian data rekam medis.

\section{Tabel 1. Test Case Data Rekam Medis}

\begin{tabular}{|c|c|c|c|c|}
\hline No. & Nama Tes & Tes Prosedur & Hasil yg diharapkan & Hasil \\
\hline 1. & $\begin{array}{lll}\text { Buka form daftar } \\
\text { periksa }\end{array}$ & $\begin{array}{lll}\text {-klik menu daftar } \\
\text { periksa }\end{array}$ & $\begin{array}{ll}\text { - halaman terbuka } \\
\text { dengan data antrian } \\
\text { pasien termuat }\end{array}$ & PASS \\
\hline 2. & $\begin{array}{l}\text { Tambah data rekam } \\
\text { medis tanpa diisi atau } \\
\text { salah satu tidak diisi }\end{array}$ & $\begin{array}{l}\text { - Klik tombol tambah } \\
\text { - klik tombol tambah } \\
\text { pada form }\end{array}$ & $\begin{array}{l}\text { Muncul peringatan data } \\
\text { tidak valid }\end{array}$ & PASS \\
\hline 3. & $\begin{array}{l}\text { Tambah data diisi } \\
\text { penuh }\end{array}$ & $\begin{array}{l}\text { - Klik tombol tambah } \\
\text { - Isi isian } \\
\text { - Klik simpan }\end{array}$ & $\begin{array}{l}\text { Muncul notifikasi data } \\
\text { berhasil dimasukkan. }\end{array}$ & PASS \\
\hline 4. & $\begin{array}{l}\text { Ubah data dengan diisi } \\
\text { form yang mau di ubah }\end{array}$ & $\begin{array}{l}\text { - Klik tombol ubah di } \\
\text { salah satu data } \\
\text { - Ubah isian } \\
\text { - Klik ubah }\end{array}$ & $\begin{array}{l}\text { Muncul notifikasi data } \\
\text { berhasil diperbarui. }\end{array}$ & PASS \\
\hline 5. & $\begin{array}{l}\text { Ubah data dengan isian } \\
\text { kosong }\end{array}$ & $\begin{array}{l}\text { - Klik tombol ubah di } \\
\text { salah satu data } \\
\text { - Ubah isian dengan } \\
\text { salah satu tanpa isian } \\
\text { kosong } \\
\text { - Klik Ubah }\end{array}$ & $\begin{array}{l}\text { Muncul peringatan data } \\
\text { tidak valid }\end{array}$ & PASS \\
\hline
\end{tabular}




\section{KESIMPULAN}

Terdapat beberapa kesimpulan yang dapat diambil dari proses pembuatan aplikasi Sistem Informasi Pengelolaan Data Pasien Rawat Jalan Klinik Pratama Anugrah Demak Berbasis Web Dengan Notifikasi Telegam. Kesimpulan yang dapat diambil antara lain:

a. Proses pendaftaran antrian pasien lebih efektif karena pasien bisa melakukan pendaftaran secara online dan aplikasi ini menyajikan fitur notifikasi Telegram untuk pasien dapat mengetahui daftar nomer antrian melalui notifikasi Telegram tersebut.

b. Dokter dapat mengetahui pasien yang telah mendaftar pada data antrian pendaftaran sehingga dokter bisa melihat terlebih dahulu pasien yang akan ditemui.

c. Aplikasi ini menyajikan fitur yang dapat mempermudah bagian administrasi untuk melakukan pencatatan pendaftaran dan pembayaran tagihan pasien. Serta bagian administrasi dapat melihat tindakan pasien baik data tindakan yang lama maupun data tindakan yang baru karena terdapat fitur untuk melihat data rekam medis pasien.

\section{DAFTAR PUSTAKA}

[1] Haryanto, \& Firmansyah, A. M. (2019). Sistem Informasi Pengolahan Data Pasien Berbasis Web Pada Klinik Yadika Tangerang.

[2] Astuti, R., \& Kristianto, K. (2018). Analisis dan Perancangan Sistem Informasi Rawat Jalan Pada Klinik ST Di Bandung

[3] Indarti, \& Laraswati, D. (2018). Rancang Bangun Sistem Informasi Pelayanan Kesehatan Berbasis Web Pada Klinik Umum Galur Medika Jakarta Pusat.

[4] Rizky, \& Widjaja. (2018). Rancang Bangun Sistem Informasi Administrasi Rawat Jalan Pada Klinik Andalan.

[5] Silalahi, Hermawati, \& Kurniawan. (2018). Aplikasi Pengolahan Data Pasien Rawat Jalan Klinik Siliwangi Baleendah Bandung Berbasis Web dan SMS Gateway .

[6] Sukamto, \& Shalahuddin. (2018). Pengertian Metode Pengembangan Sistem. 